\title{
Evaluation of water quality pollution indices for groundwater resources of New Damietta, Egypt
}

\begin{abstract}
Ground water is the most important source of domestic and irrigation purpose in both rural and urban regions. The present study is carried out to find the ground water quality by heavy metal concentration from three sites. Nine heavy metals were selected $(\mathrm{Cd}, \mathrm{Pb}, \mathrm{Cr}$, $\mathrm{As}, \mathrm{Cu}, \mathrm{Hg}, \mathrm{Se}, \mathrm{Zn}$ and $\mathrm{Ni}$ ). It was showed that concentration values were $0.0016-0.0016$, $0.003-0.00,0.006-0.00,0.00-0.004$ and $0.002 \mathrm{mg} / \mathrm{L}$, respectively. To assess ground water quality which contaminated by heavy metals, four indices were selected as follow: heavy metal pollution index (HPI), contamination index (Cd), metal enrichment index (MEI) and metal evaluation index (HEI). Results showed that the concentrations of heavy metals in water samples are within the permissible WHO limits in drinking water. Three metals of them (AS, Hg and $\mathrm{Se}$ ) were not detected in all sampling stations. MEI in the ground water samples show that $\mathrm{N}_{\mathrm{i}}$ is the highest metal enrichment value of -0.6. HPI of water samples in three sites were 20.57 which was lower than 100 the critical value for drinking water. $\mathrm{C}_{\mathrm{d}}$ shows that the values vary between -5.1 to -0.3 which indicate low contamination. HEI shows that the values in spring season vary from 0.001 to 0.66 and indicate low heavy metal pollution. Results show that ground water of the present study is acceptable for drinking.
\end{abstract}

Keywords: ground water, water quality, pollution indices
Volume 2 Issue $6-2017$

\author{
Hazem T Abd El- Hamid,' Talaat A Hegazy² \\ 'Department of Marine pollution, National Institute of \\ Oceanography and Fisheries, Egypt \\ ${ }^{2}$ Departments of Environmental Sciences, Damietta University, \\ Egypt
}

\begin{abstract}
Correspondence: Hazem T Abd El- Hamid, Department of Marine pollution, National Institute of Oceanography and Fisheries, Egypt, Tel 002-010-034-329-86,

Email hazem_ecology@yahoo.com
\end{abstract}

Received: July II, 2017 | Published: October 26, 2017

\section{Introduction}

Today heavy metals contamination of the groundwater is one of the serious environmental problems. Some of the heavy metals considered as micronutrients can cause adverse effects to human health when their contents exceed the permissible limit in drinking water. ${ }^{1}$ Thus, heavy metals assessment in groundwater used for drinking purpose is very significance from the human health viewpoint. Heavy metals are usually present in trace amounts in natural water but many of them are toxic even at very low concentration though many of the metals are essential components of the biological system. Metals such as $\mathrm{As}, \mathrm{Pb}$, $\mathrm{Cd}, \mathrm{Ni}, \mathrm{Hg}, \mathrm{Cr}, \mathrm{Co}, \mathrm{Zn}$ and Se are highly toxic even in minor quantity. Increasing amount of heavy metals in aquatic resources is currently an area of greater concern especially since a large number of industries discharge their metal containing wastes into fresh water without any acceptable treatment. ${ }^{2}$ The waste water without any treatment may cause adverse effect on the health of human, domestic animals, wildlife and environment. Contaminated ground water has deteriorated the drinking water and impacts on soil systems and crop productivity. Contaminated water when used for irrigation purpose affects soil quality and crop health of the agricultural system. The textile effluent had consisting high concentration of trace heavy metals and through its accumulation in different trophic levels of ecosystem ultimately cause the health hazards among livestock and human beings. ${ }^{3}$ So, it is very much essential to assess the quality of wastewater before discharging it and to develop an economical method for the prevention and control of ground water pollution. Ground water contaminated by textile effluents, has impact on agriculture irrigation, drinking utilities, soil and agricultural systems. ${ }^{4}$ For evaluation of water quality contamination, several methods such as the contamination index (Cd), metal enrichment index (MEI), the heavy metal pollution index (HPI) and the heavy metal evaluation index (HEI) were developed. These indices help assessing the present level of pollution in water resources and combine all the water pollution parameters into some easy approach. ${ }^{5}$ The main objective of the study is To examine heavy metal concentration in groundwater of New Damietta and To suggest the suitable indices to evaluate groundwater quality.

\section{Materials and methods}

\section{Study area}

DNM Textile Company was incorporated in 2011 in city of Damietta, Egypt with $100 \%$ Turkish capital. DNM is a vertically integrated denim fabric production plant constructed at the Public Free Zone on an outdoor area of 150.000 square meters with an indoor area of 130.000 square meters fitted with the state-of-the-art technological machinery. DNM produces 50 tons of yarn on daily basis. With the total annual production capacity of 25 million meters, the annual production capacity of the plant aimed after completion of the 2nd phase in the forthcoming term will be 50 million meters (Figure 1).

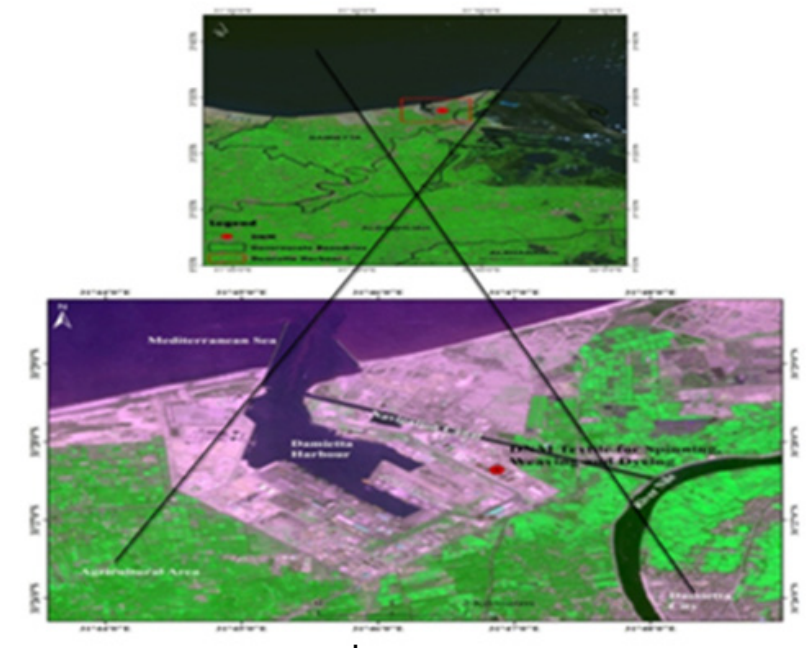

Figure I Location map of the study area. 


\section{Sample analysis}

Ground water and soil samples were collected from three locations at DNM textile company (Damietta). Sampling locations (Spinning, Weaving and Dyeing) were selected as an indicator of textile industry.

\section{Digestion and analysis}

Water samples were acidified in the field with concentrated $\mathrm{HNO}$ $(5 \mathrm{ml} / 1$ of water sample to reduce the $\mathrm{pH}$ of the sample, $\mathrm{pH}>2.0)$ for the total metal estimation. Total metal content in soil was determined by digesting $0.5 \mathrm{~g}$ of soil/ sediment sample from each site with a mixture of Conc $\mathrm{HNO}_{3}$ and $\mathrm{HClO}_{4}(10 \mathrm{ml}+2 \mathrm{ml})$. The digested samples were filtered through Whatman filter No. 42 and finally volumes were made $10 \mathrm{ml}$ with $0.1 \mathrm{~N} \mathrm{HNO}_{3}$ and analyzed for heavy metals using Atomic Absorption Spectrophotometer (Model ECIL-4129).

\section{Heavy metals assessment in water}

Metal pollution index (MI): This index indicates the total quality of water with respect to heavy metals and based on weighted arithmetic quality mean method and developed in two steps. First by establishing a rating scale for each selected parameter-giving weightage and second by selecting the pollution parameter on which the index is to be based. The rating system is an arbitrarily value between zero to one and its selection depends upon the importance of individual quality considerations in a comparative way or it can be assessed by making values inversely proportional to the recommended standard $(\mathrm{Si})$ for the corresponding parameter as proposed earlier Prasad and Bose. ${ }^{6}$ HPI is calculated from equation below:

$$
H P I=\sum_{i=1}^{n} W i Q i / \sum_{i=1}^{n} W i
$$

$\mathrm{Q}_{\mathrm{i}}=$ the sub-index of the parameter, $\mathrm{W}_{\mathrm{i}}=$ the unit weightage of the parameter, $n=$ the number of parameters considered, the sub-index $\left(\mathrm{Q}_{\mathrm{i}}\right)$ of the parameter is calculated by where

$$
Q_{i}=\sum_{i=1}^{n}(M i-I i / S i-I i) * 100
$$

$\mathrm{M}_{\mathrm{i}}=$ the monitored value of heavy metal of parameter, $\mathrm{Ii}=$ the ideal value of the parameter, $\mathrm{Si}=$ the standard value of the parameter. The sign (-) indicates numerical difference of the two values, ignoring the algebraic sign. HPI 100 indicated that high heavy metal pollution (critical pollution index). If the HPI values of water samples were greater than 100 , water is not potable. The weightage was taken as the inverse of $\mathrm{MAC}, \mathrm{Si}$ the $\mathrm{WHO}^{7}$ standard for drinking water and Ii the guide value for the selected element.

Contamination index $\left(\mathbf{C}_{\mathrm{d}}\right)$ : In this method, the water quality is assessed by the calculation of the degree of contamination and computed separately for each sample of water analyzed, as a sum of the contamination factors of individual components exceeding the upper permissible value was taken as the maximum admissible concentration (MAC). Hence, the $\mathrm{C}_{\mathrm{d}}$ summarizes the combined effects of several quality parameters considered harmful to household water. The $\mathrm{C}_{\mathrm{d}}$ is calculated from equation below:

$$
\begin{gathered}
C_{d}=\sum_{i=1}^{n} C f \\
C f=\frac{C_{a}}{C_{n}}-1
\end{gathered}
$$

Where Cfi is contamination factor for the component, $\mathrm{C}_{\mathrm{a}}$ is analytical value for the component and $\mathrm{C}_{n}$ is upper permissible concentration of the component. The resultant $C_{d}$ value which are grouped into three categories as follows: $\mathrm{C}_{\mathrm{d}}<1$ (low), $\mathrm{C}_{\mathrm{d}}=1-3$ (medium) and $\mathrm{Cd}>3$ (high). ${ }^{8}$
Metal Evaluation Index (HEI): Heavy metal evaluation index with focus on heavy metals in water samples for estimating the water quality. This index classify into three categories, which include HEI $<\mathrm{HEI}<800$ (moderate to heavy metals) and HEI $>800$ (high heavy metals). The index is calculated from the following equation Mohan et al. (1996):

$$
H E I=\sum_{i=1}^{n} \frac{H_{c}}{H_{m a c}}
$$

$\mathrm{H}_{\mathrm{c}}=$ the monitored value of the parameter.

$\mathrm{H}_{\text {mac }}=$ the maximum admissible concentration of the parameter.

Metal Enrichment Index (MEI): Metal enrichment index (MEI) of heavy metals in the surface water samples were calculated using the formula:

$$
M E I=\frac{C_{i}-C_{0}}{C_{0}}
$$

Metal Enrichment Index Where $\mathrm{Ci}$ is the total concentration of each metal $\mathrm{i}$ measured in the water samples; $\mathrm{C}_{\mathrm{o}}$ is the heavy metal background established for the system studied. The WHO maximum permissible limits of metals in water were used as the background value for the metals.

Table I Mean concentration of heavy metals $(\mathrm{mg} / \mathrm{L})$ in water samples

\begin{tabular}{lllll}
\hline Parameters & Site I & Site 2 & Site 3 & Mean \\
\hline Cadmium & 0.002 & 0.002 & 0.001 & 0.0016 \\
Lead & 0.001 & 0.002 & 0.002 & 0.0016 \\
Chromium & 0.003 & 0.003 & 0.003 & 0.003 \\
Arsenic & 0 & 0 & 0 & 0 \\
Copper & 0.003 & 0.002 & 0.013 & 0.006 \\
Mercury & 0 & 0 & 0 & 0 \\
Selenium & 0 & 0 & 0 & 0 \\
Zinc & 0.006 & 0.004 & 0.004 & 0.004 \\
Nickel & 0.001 & 0.005 & 0.002 & 0.002 \\
\hline
\end{tabular}

\section{Results and discussion}

Results showed that heavy metals concentrations $(\mathrm{Cd}, \mathrm{Pb}, \mathrm{Cr}$, $\mathrm{As}, \mathrm{Cu}, \mathrm{Hg}, \mathrm{Se}, \mathrm{Zn}$ and $\mathrm{Ni}$ ) were detected in water samples in this present study. The mean concentrations of heavy metals in water samples were: $0.0016-0.0016,0.003-0.00,0.006-0.00,0.00-$ 0.004 and $0.002 \mathrm{mg} / \mathrm{L}$ respectively Table 1 . Results showed that the concentrations of heavy metals in water samples are within the permissible WHO limits in drinking water. Three metals of them (AS, $\mathrm{Hg}$ and $\mathrm{Se}$ ) were not detected in all sampling stations. HPI of water samples in three sites were 20.57 which was lower than 100 the critical value for drinking water. Abdullah ${ }^{9}$ calculated the HPI and MI for Euphrates River before confluence with Tigris River at Qurmat-Ali. The mean value of HPI was found to be below the critical pollution index value of 100 . Cd shows that the values vary between -5.1 to -0.3 which indicate low contamination. HEI shows that the values vary from 0.001 to 0.66 and indicate low heavy metal pollution (Table 2). The lower values of HPI and HEI reported in present study of can be interpreted in terms of absence of the local anthropogenic sources. ${ }^{9}$ Yari \& Sobhanardakani ${ }^{10}$ reported that The $\mathrm{Cd}$ and HEI values in Iran are found below the critical pollution index (100), and this indicates the water is not critically polluted with respect to studied heavy metals. Water quality pollution indices for groundwater resources of Ghahav and Plain in Iran estimated as the following indices Cd, HPI and HEI in samples as $-2.27,9.01$ and 1.73 , respectively that indicates low contamination levels. ${ }^{11,12}$ (Figures 2-4). MEI in the ground water 
samples shows that $\mathrm{Ni}$ is the highest metal enrichment value of -0.6 . One way ANOVA show that there is no significant among heavy metals concentrations (Table 3). f- Value among heavy metals show no obvious significant that calculated as follow $\mathrm{f}=2.84$ and $\mathrm{p}$-value $=0.03$. F-Value $=0.31$ and $\mathrm{p}$ - value $=0.73$. A comparison between the indices and heavy metal concentrations show strong negative correlation between $\mathrm{Cd}$ and $\mathrm{Cu}\left(-0.997^{*}\right)$. This indicates that $\mathrm{Pb}$ is the main contributory parameters. In addition, the correlation between $\mathrm{Pb}, \mathrm{HPI}$ and HEI is negative significant (Table 4). Correlation analysis provides an effective way to reveal the relationships between multiple variables and thus have been helpful for understanding the influencing factors as well as the sources of chemical components. ${ }^{13,14}$

Table 2 Heavy metal pollution indices (HPI, HEl and Cd) of water samples

\begin{tabular}{|c|c|c|c|c|c|c|c|c|c|c|c|}
\hline Metas & Site I & Site2 & Site3 & li & Si & Qi & $\mathbf{W i}$ & $\mathbf{W i * Q i}$ & HEI & Cd & MEI \\
\hline $\mathrm{Cd}$ & 2 & 2 & I & 3 & 5 & 50 & 0.3 & 15 & 0.66 & -0.3 & 0 \\
\hline $\mathrm{Pb}$ & I & 2 & 2 & 10 & 100 & 10 & 0.7 & 7 & 0.1 & -0.9 & -0.95 \\
\hline $\mathrm{Cr}$ & 3 & 3 & 3 & 50 & 50 & 0 & 0.02 & 0 & 0.06 & -0.9 & -0.82 \\
\hline As & 0 & 0 & 0 & 0 & 0 & 0 & 0 & 0 & 0 & 0 & 0 \\
\hline $\mathrm{Cu}$ & 3 & 2 & 13 & 1000 & 1000 & 0 & 0.001 & 0 & 0.001 & -0.9 & -0.98 \\
\hline $\mathrm{Hg}$ & 0 & 0 & 0 & 0 & 0 & 0 & 0 & 0 & 0 & 0 & 0 \\
\hline $\mathrm{Se}$ & 0 & 0 & 0 & 0 & 0 & 0 & 0 & 0 & 0 & 0 & 0 \\
\hline $\mathrm{Zn}$ & 6 & 4 & 4 & 3000 & 5000 & 149.8 & 0.0002 & 0.02 & 0.002 & -0.9 & -0.99 \\
\hline $\mathrm{Ni}$ & I & 5 & 2 & 20 & 20 & 0 & 0.05 & 0 & 0.05 & -0.9 & -0.6 \\
\hline $\mathrm{HPI}=20.57$ & & & & & & & 1.07 & 22.02 & - & - & - \\
\hline
\end{tabular}

Table 3 One-Way ANOVA among heavy metals and three sites in water samples

$\begin{array}{llllllllll}\text { Metals } & \mathrm{Cd} & \mathrm{Pb} & \mathrm{Cr} & \mathrm{As} & \mathrm{Cu} & \mathrm{Hg} & \mathrm{Se} & \mathrm{Zn} & \mathrm{Ni} \\ \text { Variance } & 0.3 & 0.3 & 3 & 3 & 3 & 3 & 3 & 1.3 & 4.3 \\ \text { Mean } & \mathrm{I} .6 & 1.6 & 3 & 0 & 6 & 0 & 0 & 4.6 & 2.6\end{array}$

$\mathrm{f}$ - value $=2.84 \mathrm{p}$ - value $=0.03$

At the 0.0 I level, the means are NOT significantly different

Variance Site I Site 2 Site 3

$\begin{array}{lll}3.9 & 3.2 & 16.6\end{array}$

F- value $=0.31163 \mathrm{p}$ - value $=0.73517$

At the 0.0 I level, the means are NOT significantly different

Table 4 correlation matrix among heavy metals and indices

\begin{tabular}{lllllll}
\hline Metals & $\mathbf{C d}$ & $\mathbf{P b}$ & $\mathbf{C u}$ & $\mathbf{N i}$ & HEI & $\mathbf{C d I}$ \\
\hline $\mathrm{Cd}$ & $\mathrm{I}$ & - & - & - & - & - \\
$\mathrm{Pb}$ & -0.5 & $\mathrm{I}$ & - & - & - & - \\
$\mathrm{Cu}$ & $-0.997^{*}$ & 0.427 & $\mathrm{I}$ & - & - & - \\
$\mathrm{Ni}$ & 0.28 & 0.693 & -0.36 & $\mathrm{I}$ & - & - \\
$\mathrm{HEl}$ & 0.55 & $-0.998^{*}$ & -0.48 & -0.649 & $\mathrm{I}$ & - \\
$\mathrm{Cdl}$ & 0.5 & $-1.000^{*}$ & -0.43 & -0.693 & 0.1 & $\mathrm{I}$
\end{tabular}

*Correlation is significant at the 0.05 level (2-tailed).

**Correlation is significant at the 0.0 I level (2-tailed).

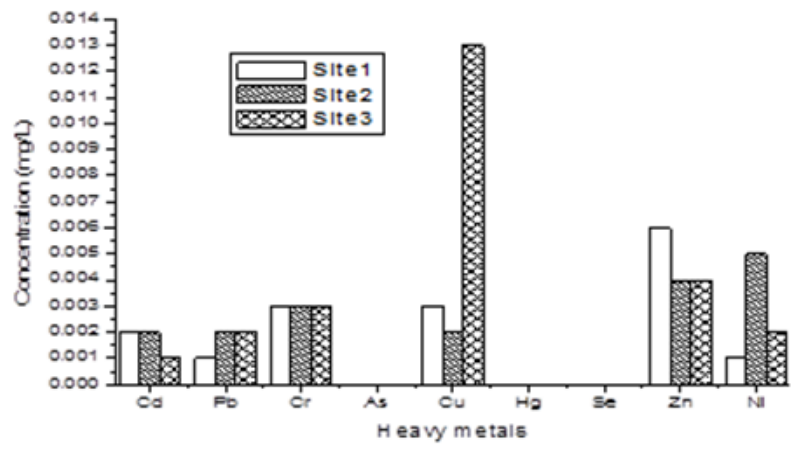

Figure 2 Heavy metals concentration in water sample.

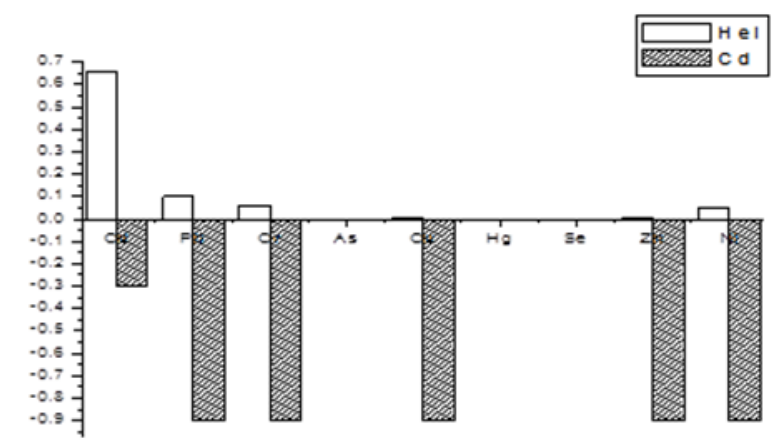

Figure 3 contamination and evaluation indices of water heavy metals.

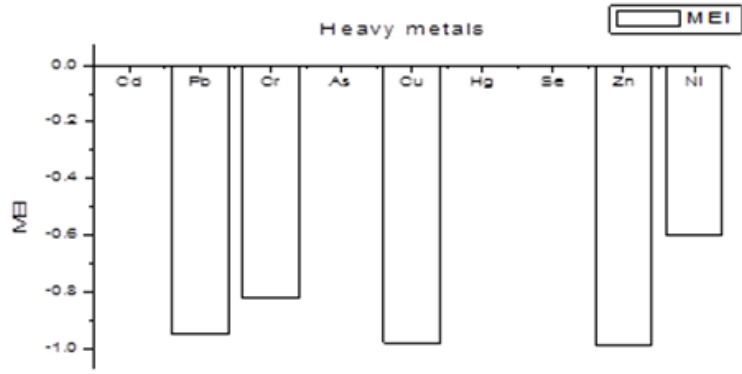

Figure 4 Metal enrichment index of heavy metals in ground water. 


\section{Conclusion}

Heavy metal pollution was not observed in any sites. According to the water quality indices, water samples of the study area have been identified suitable for drinking. Therefore, the water quality indices proved to be a very useful tool in evaluating overall pollution of the ground water. However, the values of these three indices in totally below the critical values but severe precautions consideration such as manage the use of agricultural inputs, prevention of use of wastewater and sewage sludge in agriculture, control of overuse of organic fertilizers and establishment of pollutant industries are recommended in this area.

\section{Acknowledgments}

None.

\section{Conflicts of interest}

The authors declare there is no conflict of interests.

\section{Funding}

None.

\section{References}

1. Prasad B, Kumari P, Bano S, et al. Ground water quality evaluation near mining area and development of heavy metal pollution index. Appl Water Sci. 2014;4(1):11-17.

2. Canter LW. Ground water quality protection, Lewis publications. Inc., Chelsea, M1, USA; 1987. 650 p.

3. Malik DS, Yadav R, Bharti PK. Accumulation of heavy metals in crop plants through irrigation of contaminated ground water in Panipat region. Environmental Conservation Journal. 2004;5:101-104.
4. Bharti PK, Chauhan, Avnish. Soil quality and contamination, Discovery Publishing House, Delhi, India; 2013. 186 p.

5. Maria $\mathrm{H}$, Roman $\mathrm{C}$, Ristoiu $\mathrm{D}$, et al. Assessing of water quality pollution Indices for heavy metal contamination. A study case from Medias City groundwaters. Agric Sci Pract. 2013;4:25-31.

6. Prasad B, Bose JM. Evaluation of heavy metal pollution index for surface and spring water near a limestone mining area of the lower Himalayas. Environmental Geology. 2001;41(1-2):183-188.

7. WHO. Total Dissolved Solids in Drinking Water. Background Document for Development of WHO Guidelines for Drinking Water Quality (WHO/SDE/WSH/03.04/16). 2003.

8. Nasrabadi T. An index approach to metallic pollution in river waters. Int J Environ Res. 2015;9(1):385-394.

9. Abdullah E. Quality assessment for Shatt Al-Arab River using heavy metal pollution index and metal index. Journal of Environment and Earth Science. 2013;3(5):114-120.

10. Yari AR, Sobhanardakani S. Water quality assessment of groundwater resources in Qaleeh Shahin Plain Based on Cd and HEI ISSN:23832568. Quarterly of International Archives of Health Sciences. 2016;3:101-106.

11. Sobhanardakani S. Evaluation of the water quality pollution indices for groundwater resources of Ghahavand Plain, Hamadan Province, and western Iran. Iran J Toxicol. 2016;10(3):35-40.

12. Li X, Liu L, Wang Y, et al. Heavy metal contamination of urban soil in an old industrial city (Shenyang) in ortheast China. Geoderma. 213;192:50-58.

13. Malik DS, Bharti PK. Textile Pollution, Daya Publishing House, Delhi, India; 2010. 383 p.

14. Mohan SV, Nithila P, Reddy SJ. Estimation of heavy metals in drinking water and development of heavy metal pollution index. J Environ Sci Health A. 1996;31(2):283-289. 